\title{
Predication of the SMR Critical Core Performance Under Zero Power
}

\author{
Magy Kandil Salwa Helmy Ahmed Refaey \\ Nuclear and Radiological Regulatory Authority (NRRA), Cairo, Egypt
}

Email address:

magy_kandil@yahoo.com

\section{To cite this article:}

Magy Kandil Salwa Helmy Ahmed Refaey. Predication of the SMR Critical Core Performance Under Zero Power. International Journal of Systems Engineering. Vol. 5, No. 1, 2021, pp. 18-24. doi: 10.11648/j.ijse.20210501.13

Received: April 8, 2021; Accepted: April 26, 2021; Published: May 8, 2021

\begin{abstract}
In Nuclear Power plants, Reactivity Induced Accidents can lead to sever accidents. Rod Ejection Accidents are part of Reactivity Induced Accidents that induced through driven by reactivity insertion due to many failures. Thus, safety analysis of core behaviour under many external rod reactivities in Nuclear power plants are mandatory by regulators or safety authorities. In this research, a new dynamic model is proposed for core safety analysis under Rod Ejection Accidents. Thermal Power and other core parameters predictions are the most important goals for any reactor operation policy, during all periods and specifically at zero power to avoid severe accidents. The proposed model involves of a point kinetics explanation of neutronics combined with thermal hydraulic dynamics in the reactor core to predict its variation of parameters during transients using MATLAB environment. The proposed model is validated through comparing with the transient dynamic responses obtained through previous research for a chosen design of NuScale small modular reactor. In addition, the proposed model is verified through determining the dynamic reactor responses of Rod Ejection Accidents at hot zero power with many perturbations of different control rod ejection. The Performed safety analysis results of validation and the verification demonstrate that, the proposed model represents the reactor core behavior during the rod ejection transients with good prediction of thermal power of core peaks. Moreover, it allowed large explorations of core safety parameters and predicting the performance of its rector core during Rod Ejection Accidents under critical Hot zero power.
\end{abstract}

Keywords: A Pressured Water Smaller Rector, Reactivity Induced Accidents, A Rod Ejection Accident, Hot Zero Power, NuScale Small Modular Reactor

\section{Introduction}

A Reactivity Initiated Accident (RIA) is an accident in a nuclear reactor wherever the reactivity is increased involuntarily consecutively fission rate and then the thermal power is increased that can lead to fail some fuel rods, or a core disruption if the energy deposited or enthalpy increase that causes severe accidents. Some scenarios concerning as RIA are recorded as Design base accidents (DBAs). Consequently, for licensing purposes, it must be verified that the reactor can survive these scenarios without a weighty fuel damage. The reactor core is protected against RIA by resources of the control safety system, however as well by the negative feedback mechanism.

The first reactivity-initiated accidents occurred in the 1950s after that in 1952, 1955 and 1961, all of which caused in severe harm and break of the reactor. The later reactivity- initiated accidents led to improve the design requirements applied in advanced generations of all types of reactors [1]. The design philosophy in NPPs is reducing the potential sources for RIAs to a minimum, and if an accident occurred, then rapidly terminating the power surge. While there are the lessons learned from early reactivity-initiated accidents, they still have occurred, such as the Chernobyl nuclear power plant in Ukraine, on April 26 1986, it is considered as a serious accident occurred due to reactivity-initiated accident in reactor 4 [2].

Reactivity insertion actions in power reactors can be divided principally into: control system failures, events caused by coolant or moderator temperature, control element ejections, void effects, and events caused by dilution or removal of coolant or moderator poison [3].

A control rod ejection accident can occur through the control rod drive mechanism failure or its housing. As a 
consequence of the control rod ejection, the reactivity of the core is quickly increased due to decrease neutron absorption.

The reactivity adding rates and the resulting power transients increased more and more, thus the control rod ejections accidents are considered design basis accidents in light water reactors. Many accidents scenarios for control rod ejections in light water reactors are additional described at [4]. Control rod ejection accidents must be avoided or control drawbacks of them specially at Zero power to keep it critical to avoid DBA. A reactor in zero power critical state is satisfying a stable fission chain reaction with no weighty growth or decays in the thermal reaction power rate and also is at a low enough level that thermal attentions are not significant to the reaction. [4]

The Pressured Water Reactor (PWR) works at zero power under to conditions Cold Zero Power (CZP) and Hot Zero Power (HZP). In Cold Zero Power condition, the reactor is at cold shutdown that is subcritical case, consequently the moderator temperature is low (below $100{ }^{\circ} \mathrm{C}$ ) and the residual power cooling process is active. At start up condition in the nuclear reactor, the cooling process is turned off and the heat-up starts, then the reactor operator drawn out control rods from the core conferring the first critical stage are reached. After that, the generated thermal power is used to heat up the reactor and to reach the full operation temperature and pressure. The control rods are drawn out in groups of four or eight then, the recirculation pumps at a low speed and the turbines are not connected [5]. Then the reactor reached to Hot zero power condition when the operation pressure and temperature is reached to near full values nonetheless the power remains low (2\%) [6]. Then, start-up with power is continued over $(2 \%)$ of full power at that time critical reactor is reached by the core heating through many control rods are removed from the core to increase power more and more to reach operation pressure and temperature. After that, the turbines are connected, and the reactor power increases up to full power. From above startup sequence, the hot zero power condition is very important to safety analysis since REA can cause sever accidents during increase the thermal power core and if the more reactivity inserted due to external control rod special above than $1 \$$.

In last recently years, the movement in small modular reactor (SMR) technology development water-cooled Integral pressurized water reactor (IPWR) type [7] that provides an enhanced safety margin and offer to use safe, clean, and in addition, a reliable nuclear energy with a broad range of energy applications, such as desalination of seawater since, they have a lot of advantages over the conventional nuclear reactors [8]. NuScale rector is an example of a manufacturer of SMRs (US-company), its design is considered integral pressurized water reactors (IPWRs) [9].

In this research, a new model of Nuclear core in a small Modular Reactor is proposed for predicting the dynamic reactor response under REA as RIA specified transients. The proposed model is consisted of a point kinetics description of neutronics and thermodynamics in the reactor core, that will be represented in the next sections. The proposed model is validated and verified within MATLAB environment. Firstly, it is compared with the same transient in Reference [10] for model validation. After that, the model verification is achieved by many specified transients of reactivity increased as REAs accidents that are investigated in refence [11], that are simulated to examine the transient reactor dynamic responses.

The physical reactor model on the NuScale SMR reactor is described in Section 2; the proposed dynamic model is represented in Section 3; the validation of the proposed is represented in section 4; section 5 represented the methodology of the proposed model verification through many positive external reactivates applied. The verification results of the proposed model applied under specified transients are described and dissection in section 6 and finally, the conclusion is presented in Sections 7.

\section{NuScale Small Modular Reactor}

The NuScale Power Module is a nuclear technology principle that concentrations on the integration of its components, simplification of systems, and also uses of passive safety features. A NuScale SMR can operate as a standalone unit or in a system of up to twelve SMR modules that are poled in vessels. Each vessel is called module and is equipped with its own steam turbine-generator and work in a common pool filled with water, to contribute an excessive safety of the reactors. Figure 1 shows the construction of a NuScale SMR.

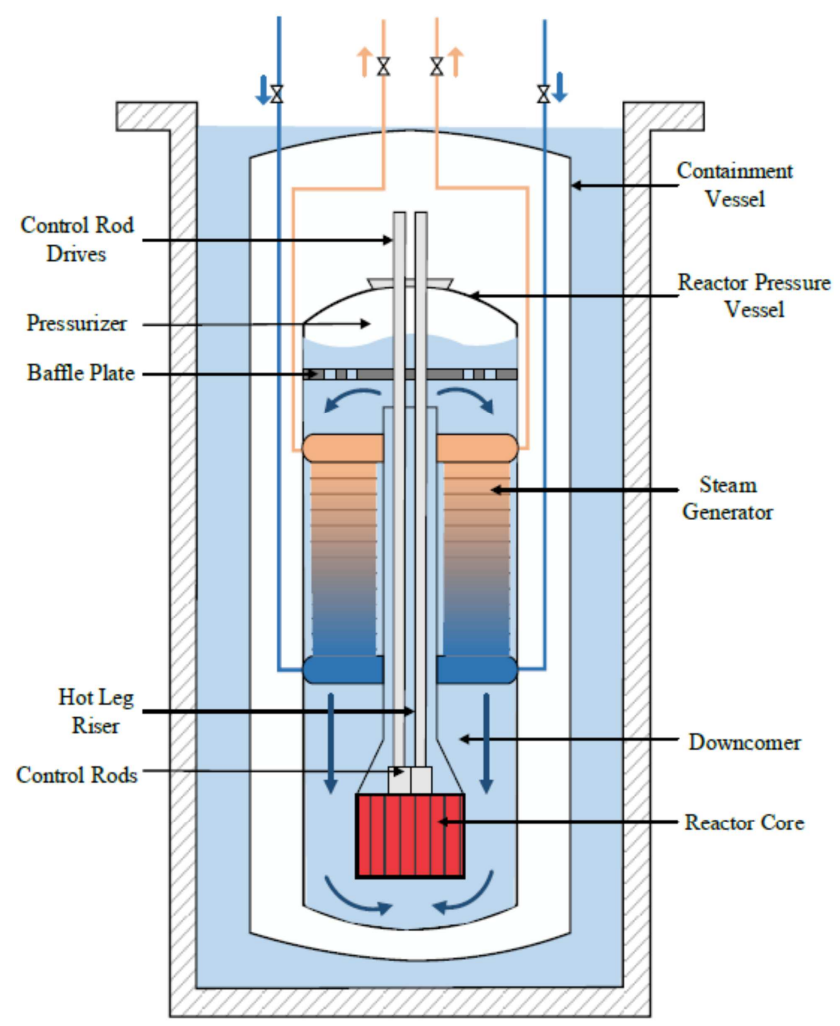

Figure 1. The construction of NuScale SMR [10]. 
The full power steady-state parameters for NuScale SMR are show in Table 1 [10].

Table 1. The Design parameters of NuScale SMR.

\begin{tabular}{ll}
\hline Parameters & Value \\
\hline Reactor thermal power & $160 \mathrm{MW}$ \\
& $45 \mathrm{MWe}$ \\
Coolant/Moderator & Light water \\
Circulation type & Natural circulation \\
Reactor operating pressure & $12.76 \mathrm{MPa}$ \\
Active core height & $2 \mathrm{~m}$ \\
Fuel material & $\mathrm{UO} 2$ ceramic pellets \\
Fuel element type & $17 \times 17$, square array \\
Cladding material & Zircaloy-4 \\
U-235 enrichment & $<4.95 \%$ \\
Fuel cycle length & 24 months \\
Steam generator type & Vertical, helical-coil \\
Number of steam generators & 2 \\
Pressurizer type & Integral \\
\hline
\end{tabular}

\section{The Proposed Model Description}

The Proposed model simulates the reactor core using a neutronics model, reactivity Model and thermal-hydraulics model as following:

\subsection{Reactor Neutron with Kinetics Equations Model}

In the Reactor neutron model, the physics of the nuclear reactor core are modeled through the point kinetics equation as differential equations. The equations contain speed diffusion equation, one neutron precursor concentration, as flowing:

$$
\begin{aligned}
& \dot{P}=\frac{\rho-\beta}{\Lambda} P+\lambda C \\
& \dot{C}=\frac{\beta}{\Lambda} P-\lambda C
\end{aligned}
$$

Where: $\mathrm{t}$ is the time of simulation; $P$ is the fractional reactor power, $\rho$ is the reactivity of the system; $\beta$ is the total delayed neutron fractions; $\Lambda$ is the neutron mean lifetime; $\lambda$ is the decay constant for the delayed neutron precursor and $C$ is the concentration of the delayed neutron.

\subsection{Reactivity Model}

The input reactivity used in Point Kinetics Equations is the net reactivity from several sources, among these, are control rod reactivity, reactivity from changes-based on fuel temperature, moderator changes, and fission product poisons.

Approximately fission products have a high neutron absorption cross-section, Xenon-135. This poison affects the neutron population in the reactor due to their high neutron absorption capacity [12]. Xenon-135 is a product of Iodine135 that has a 7 hours' half-life [13]. The decay of I-135 to $\mathrm{Xe}-135$ is, in practice, the only way in which iodine is lost. (Removal of $\mathrm{I}-135$ by radiative capture is negligible compared to its decay because I-135 has a very small absorption cross section). There are two loss mechanisms for xenon; both burnup and decay are important removal processes [13]. At high power, neutron-capture removes much more xenon than does beta decay. An important point is that burnup changes immediately when flux changes, while the 9.1-hour beta decay half-life governs its decay rate [14]. During the steady state operation of the reactor, the Xenon135 concentration will be a build-up to equilibrium value in about 50 hours [15]. The effect of control rod movement, fuel, coolant (Moderator) temperatures feedback and Xenon135 as fission product poison are incorporated into Point Kinetics equations-based model. Derived linear point kinetics equations and linear thermal-hydraulic equations are used to form the proposed model using MATLAB. The reactivity term $(\rho)$, are linearized as flowing:

$$
\begin{gathered}
\partial \rho=\left(\partial \mathrm{T}_{\mathrm{f}}\right) \alpha_{\mathrm{f}}+\left(\partial \mathrm{T}_{\mathrm{C} 1}+\partial \mathrm{T}_{\mathrm{C} 2}\right) \frac{1}{2} \alpha_{\mathrm{C}}+\partial \rho_{\mathrm{ext}}+\partial \rho \mathrm{xe} \\
\partial \dot{\mathrm{I}}=\gamma_{\mathrm{I}}(\partial \mathrm{P})-\lambda_{\mathrm{I}}(\partial \mathrm{I}) \\
\partial \dot{\mathrm{x} e}=\left(\gamma_{\mathrm{xe}}-\sigma_{\mathrm{xe}}\right)(\partial \mathrm{P})+\lambda_{\mathrm{I}}(\partial \mathrm{I})-\lambda_{\mathrm{xe}}(\partial \mathrm{xe})
\end{gathered}
$$

Where: $T_{f}, T_{C 1}$, and $T_{C 2}$ are the average temperatures of the fuel and first and second coolant lumps, respectively; $\alpha_{\mathrm{F}}$ and $\alpha_{c}$ is the fuel and coolant temperature reactivity coefficient respectively; $\rho_{\mathrm{ext}}$ is the reactivity of the control rod motions; $\rho_{\mathrm{xe}}$ is the reactivity due to the Xenon; $\mathrm{Xe}$ is the xenon concentration and $\sigma_{\mathrm{xe}}$ is the microscopic absorption crosssection. $\mathrm{I}$ is the Iodine consternation; $\lambda_{\mathrm{I}}$ is iodine decay constant; $\lambda_{\mathrm{xe}}$ is the xenon decay constant; $\lambda_{\mathrm{I}}$ iodine yield; $\lambda_{\mathrm{xe}}$ is the xenon yield.

After replacing the reactivity term $(\rho)$ in Equation (1) with its equivalent, the point kinetics equations are linearized to:

$$
\begin{gathered}
\partial \dot{P}=\frac{-\beta}{\Lambda} \partial P+\lambda C+\frac{\alpha_{f} P_{0}}{\Lambda} \partial T_{f}+\frac{\alpha_{C} P_{0}}{\Lambda} \partial T_{C}+\frac{P_{0}}{\Lambda} \partial \rho_{\text {ext }}+ \\
\frac{P_{0}}{\Lambda} \partial \rho x \mathrm{x} \\
\partial \rho x \mathrm{e}=\sigma_{X e} \partial x e \\
\dot{\partial} C=\frac{\beta}{\Lambda} \partial P-\lambda C
\end{gathered}
$$

Where: $P_{0}$ is the initial reactor power.

\subsection{Reactor Thermal-hydraulics Model}

The proposed model depended on analysis of a thermal fluids system with conservation of mass, energy and momentum and assuming that the reactor coolant is at constant density, pressure and mass flow rate. The energy balance accounts for the heat transfer from the nuclear fuel to the coolant utilizes two coolant lumps for every fuel lump [10].

Introducing perturbation variables through the linearized to calculate the parameters values changes with time of form of the reactor thermal hydraulics is given by the differential equations [9-11] are used with reactor steady state parameters value are shown in table 2 [10].

$$
\begin{gathered}
\partial \dot{T_{f}}=\left(\frac{f}{m_{f} c_{p f}}\right) \partial P+\frac{U_{f c} A_{f c}}{m_{f} c_{p f}}\left(\partial T_{c 1}-\partial T_{f}\right) \\
\partial T_{c 1}^{\cdot}=\left(\frac{(1-f)}{2 m_{c 1} c_{p c}}\right) \partial P+\frac{U_{f c} A_{f c 1}}{m_{c 1} c_{p c}}\left(\partial T_{f}-\partial T_{C 1}\right)+
\end{gathered}
$$




$$
\begin{gathered}
\frac{2 \dot{m}_{c}}{m_{c}}\left(\partial T_{C i n}-\partial T_{C 1}\right) \\
\partial T_{c 2}^{\dot{*}}=\left(\frac{(1-f)}{2 m_{c 2} c_{p c}}\right) \partial P+\frac{U_{f c} A_{f c 2}}{m_{c 2} c_{p c}}\left(\partial T_{f}-\partial T_{C 1}\right)+ \\
\frac{2 \dot{m}_{c}}{m_{c}}\left(\partial T_{C 1}-\partial T_{C 2}\right)
\end{gathered}
$$

where: $T_{i n}$ is the core inlet coolant temperature; $c_{p c}$ is the coolant heat capacity; $c_{p f}$ is the fuel heat capacity, $m_{c}$ is the mass of coolant in core, $m_{c 1}$ is the coolant mass node $1 ; m_{c 2}$ is the coolant mass node $2 ; f$ is the fraction of the thermal power; $U_{f c}$ is the heat transfer coefficient from fuel to coolant and effective; $A_{f c}$ is the heat transfer surface area; $m_{f}$ is the mass of fuel; $\dot{m}_{c}$ is the primary coolant mass flow rate.

In the proposed model, the linear Equations 6 to 11 are implemented with MATLAB environment during the simulation process.

Table 2. The parameters of the NuScale SMR.

\begin{tabular}{lll}
\hline Parameter & Value & Unit \\
\hline A & 0.000002 & $\mathrm{~s}$ \\
$A_{f c}$ & 583 & $\mathrm{~m}^{2}$ \\
$c_{p c}$ & 4.96 & $K j\left(\mathrm{Kg}^{\circ} \mathrm{C}\right)^{-1}$ \\
$c_{p f}$ & 0.467 & $K j\left(\mathrm{Kg}^{\circ} \mathrm{C}\right)^{-1}$ \\
$f$ & 0.975 & - \\
$m_{c}$ & 1466 & $K g$ \\
$m_{c 1}$ & 1233 & $K g$ \\
$m_{c 2}$ & 1233 & $K g$ \\
$m_{f}$ & 11252 & $K g$ \\
$N_{0}$ & 160 & $\mathrm{MW}$ \\
$U_{f c}$ & 1135 & $\mathrm{Wm}^{2 \circ} \mathrm{C}^{-1}$ \\
$\dot{m}_{c}$ & 708 & $K g \mathrm{~s}^{-1}$ \\
$T_{f}$ & 504 & ${ }^{\circ} \mathrm{C}$ \\
$T_{C 1}$ & 268.3 & ${ }^{\circ} \mathrm{C}$ \\
$T_{C 2}$ & 291 & ${ }^{\circ} \mathrm{C}$ \\
$T_{i n}$ & 245 & ${ }^{\circ} \mathrm{C}$ \\
$\alpha_{C}$ & $-1.08 \times 10^{-4}$ & ${ }^{\circ} \mathrm{C}^{1}$ \\
$\alpha_{f}$ & $-2.16 \times 10^{-5}$ & ${ }^{\circ} \mathrm{C}^{-1}$ \\
$\beta$ & 0.007 & - \\
$\Lambda$ & 0.1 & $\mathrm{~s}^{-1}$ \\
$\lambda_{\mathrm{I}}$ & $2.87 \times 10^{-5}$ & $\mathrm{~s}^{-1}$ \\
$\lambda_{\mathrm{xe}}$ & $2.09 \times 10^{-5}$ & $\mathrm{~s}^{-1}$ \\
$\gamma_{\mathrm{I}}$ & 0.0639 & - \\
$\gamma_{\mathrm{xe}}$ & 0.00237 & - \\
$\alpha_{\mathrm{xe}}$ & $2.6500 \times 10^{-4}$ & $\mathrm{~cm}^{-2}$ \\
$\Sigma_{\mathrm{f}}$ & 28.4956 & $\mathrm{~cm}^{-1} . \mathrm{s}^{-1}$ \\
\hline & &
\end{tabular}

\section{Validation of the Proposed Model}

A comparison of reactor core dynamic simulations between the proposed model and previously published in reference [10] are implemented through considering the case of positive reactivity insertion simulated by adding a $0.01 \$$ as a step reactivity increasing at $\mathrm{t}=0 \mathrm{sec}$ and increase inlet temperate $10 \%\left(2.45^{\circ} \mathrm{C}\right)$ at full power steady state and $\mathrm{t}=0$ sec which are as supposed in reference [10]. The comparison results between change of the thermal power and the other output variables of reference [10] with results of the proposed model are shown in Figures (2-6). In both models the transient changes in the thermal power and other variables of the reactor systems are in the same trend (see reference [10]).

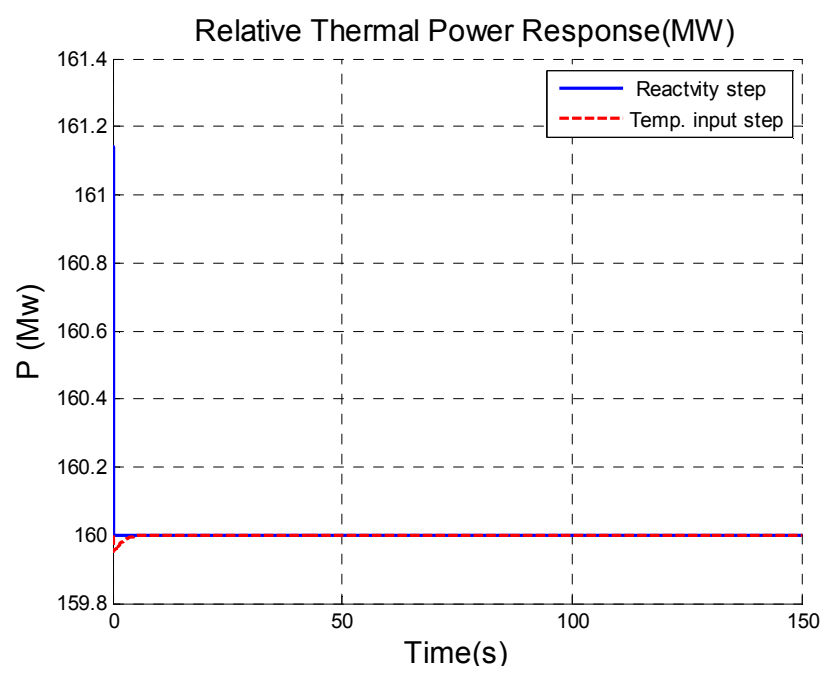

Figure 2. The reactor thermal power response to external reactivity and inlet temperature step.

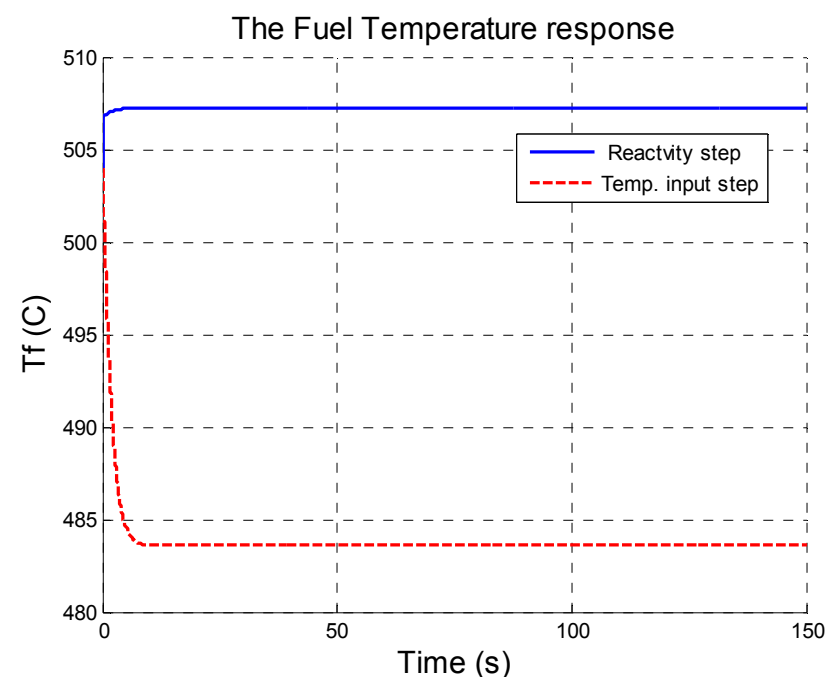

Figure 3. Fuel temperature response to external reactivity and inlet temperature step.

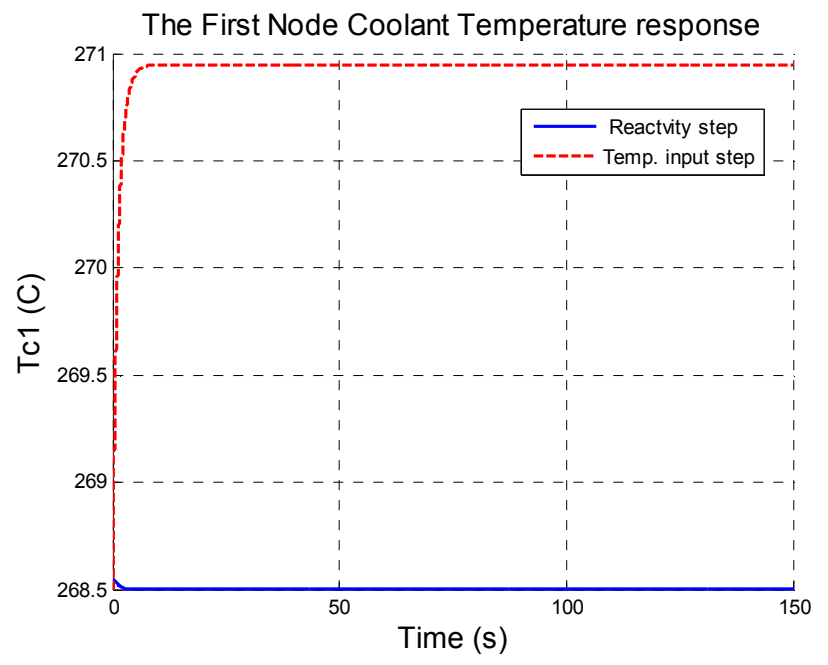

Figure 4. The first coolant temperature response to external reactivity and inlet temp step. 


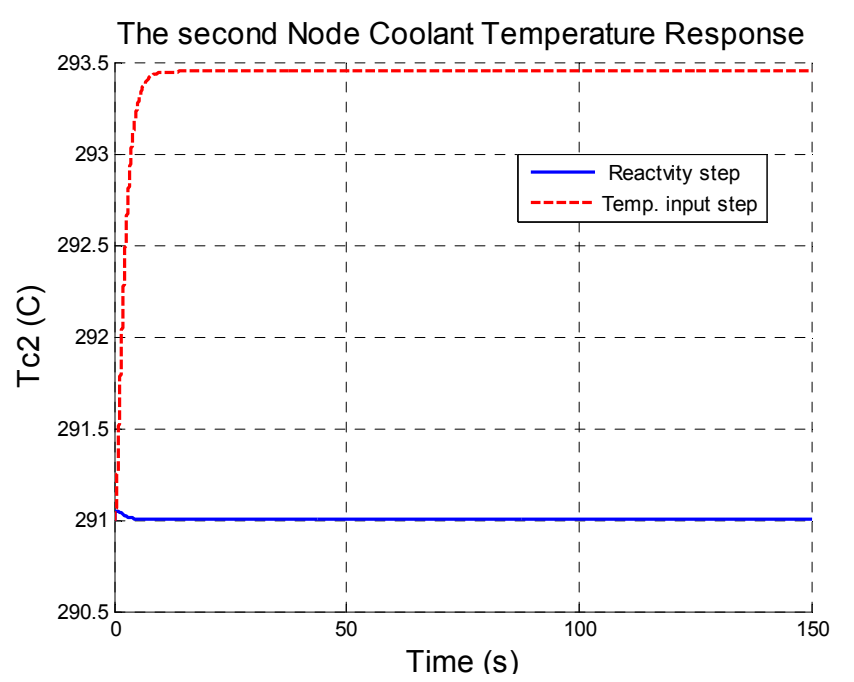

Figure 5. The second coolant temperature response to external reactivity and inlet temp step.

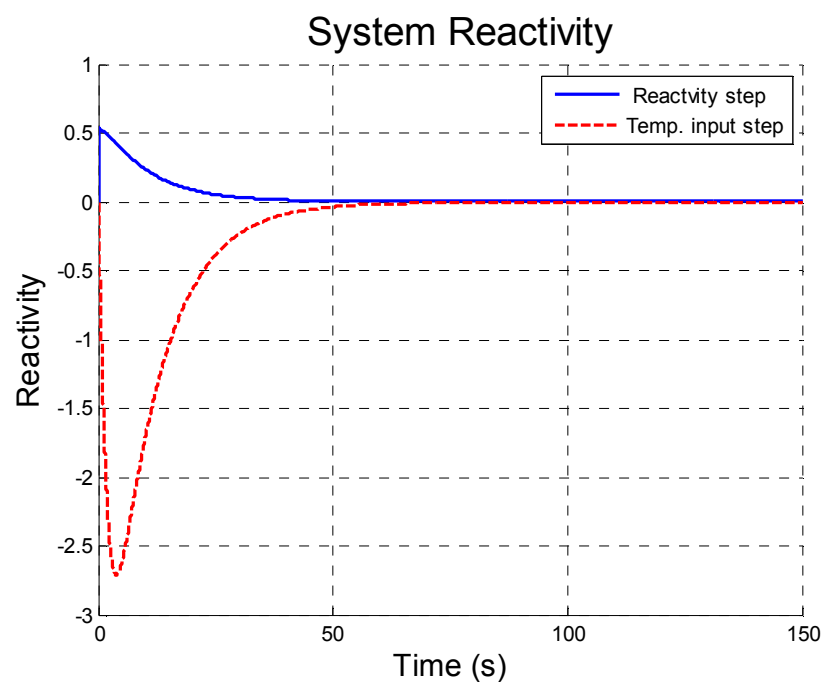

Figure 6. The system Reactivity response to external reactivity and inlet temperature step.

\section{The Verification of the Proposed Model}

The verification of the proposed model is realized by simulated NuScale reactor core as SMR when the reactor is at hot zero power, to computational study hypothesized control rod ejection accidents (REAs). In these REAs, the Core initial conditions started with the positive reactivity insertion $(\Delta \rho / \beta)$ as investigator reference [11] $(0.5 \$ 1 \$ 1.5 \$ 2 \$)$. The ejection of the control rods is hypothesized that the core is held at hot zero power conditions and with initial changes of core variables $\left(\partial \rho, \partial C, \partial T_{f}, \partial T_{c 1}, \partial T_{c 2}\right)$ had been zero values but the initial change of power $(\partial P)$ is $2 \%$ of the full power.

\section{The Results and Discussion}

The results of adding versus $\rho_{\text {ext }}[0.5 \$ 1 \$ 1.5 \$ 2 \$]$ as a step reactivity increasing at $\mathrm{t}=0 \mathrm{sec}$ at initial power $2 \%$ an initial value from normal power this case is considered as hot zero power show that: the act of versus $\rho_{\mathrm{ext}}$ causes, the fission rate and fractional thermal core power increase congruently, prompt jump as shown in Figure 7 which illustrates the variation curve of the reactor thermal power $(\partial \mathrm{P})$ with the versus $\left(\partial \rho_{\mathrm{ext}}\right)$. Moreover, they show that the power variation curve illustrates that as larger $\partial \rho_{\mathrm{ext}}$ due to REA lead to increase power generation that causes the fuel temperature increases as shown in Figure 8 and when the fuel temperatures increase rapidly produces more heat that moves to the two core coolant temperatures, as shown in Figures (9\&10).

Due to heat-up of fuel during the assumed REA, the Doppler effect provides a negative reactivity that causes decreasing in the change of thermal power and fuel temperature. In addition, the moderator temperatures changes cause additional negative changes in reactivity feedback that lead to new steady-states for all output variables reactor.

The negative reactivity feedbacks cause the steady-state value of power level $(P)$ move from 0.18 to $0.43 \mathrm{MW}$ as shown in Figure 7 and a new steady-state of Fuel temperature $\left(T_{F}\right)$, rises from $31.485^{\circ} \mathrm{C}$ to $125.94^{\circ} \mathrm{C}$ as shown in Figure 8 . and the First Coolant temperature $\left(\mathrm{T}_{\mathrm{C} 1}\right)$ reses from $15.47^{\circ} \mathrm{C}$ to $61.89^{\circ} \mathrm{C}$, respectively as shown in Figure 9 and the second Coolant temperature $\left(\mathrm{T}_{\mathrm{C} 2}\right)$ rises from $15.86^{\circ} \mathrm{C}$ to $3.438^{\circ} \mathrm{C}$ as shown in Figure 10. In addition, Figure 11 represents the system reactivity increases as the external reactivity increase and rises from $13.2 \$$ to $113.4 \$$. The change of the I-135 Concentrations increases from $2 \times 10^{7}$ to $8.1 \times 10^{7}$ as shown in Figure12. Finally, the change of and Xe-135 Concentrations at different positive external reactivity represented in Figure 13 it shows that it increases from $0.52 \times 10^{5}$ to $2.44 \times 10^{5}$. The change of the I-135 and Xe-135 Concentrations at different positive external reactivity increased since they continue increases from HZP and can reach to steady stats after nine hours. and During the steady state operation of the reactor, the Xenon-135 concentration will be a build-up to equilibrium value in about 50 hours [15].

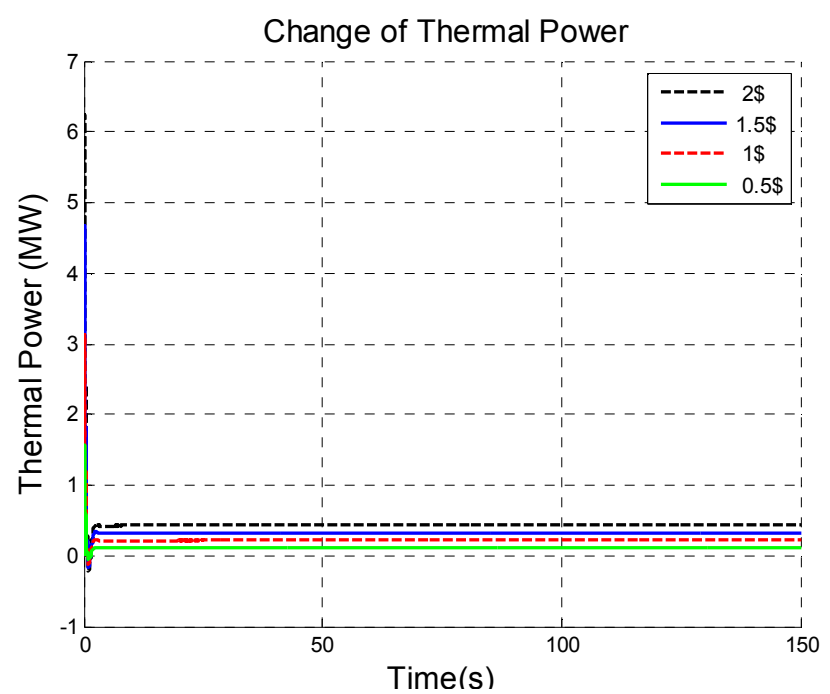

Figure 7. The change of reactor thermal power due to different external reactivity. 


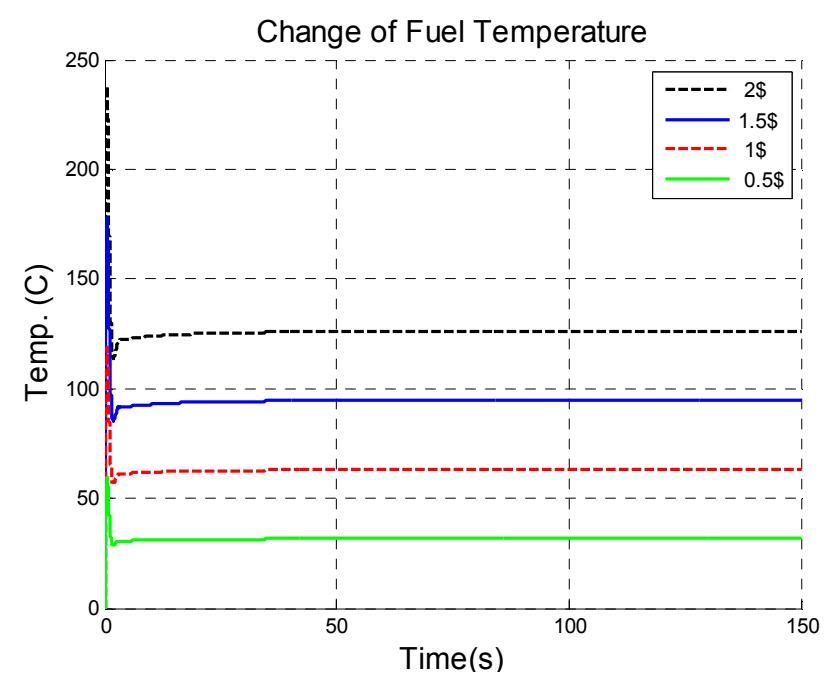

Figure 8. The change of fuel temperature. due to different external reactivity.

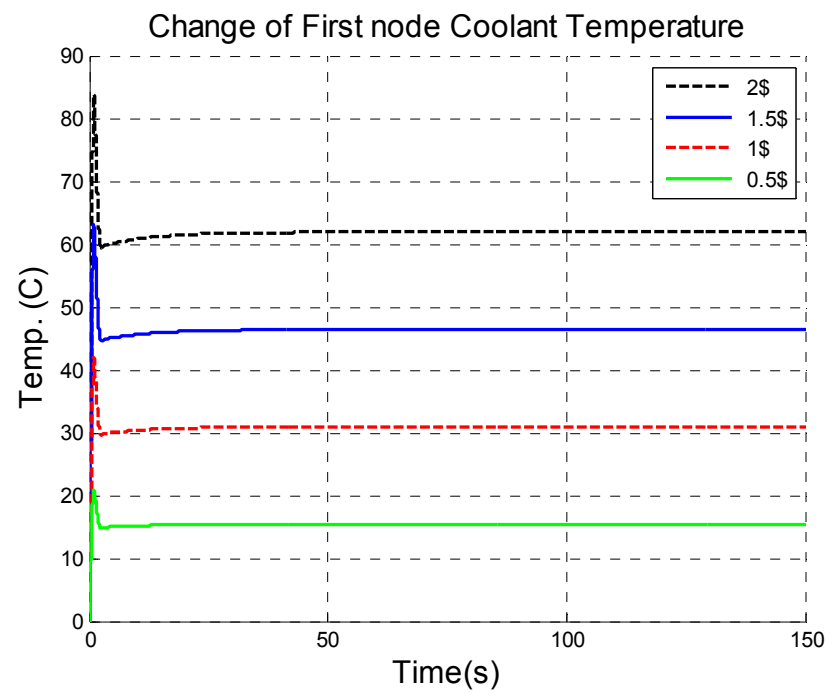

Figure 9. The change of first coolant node temperature. due to different external reactivity.

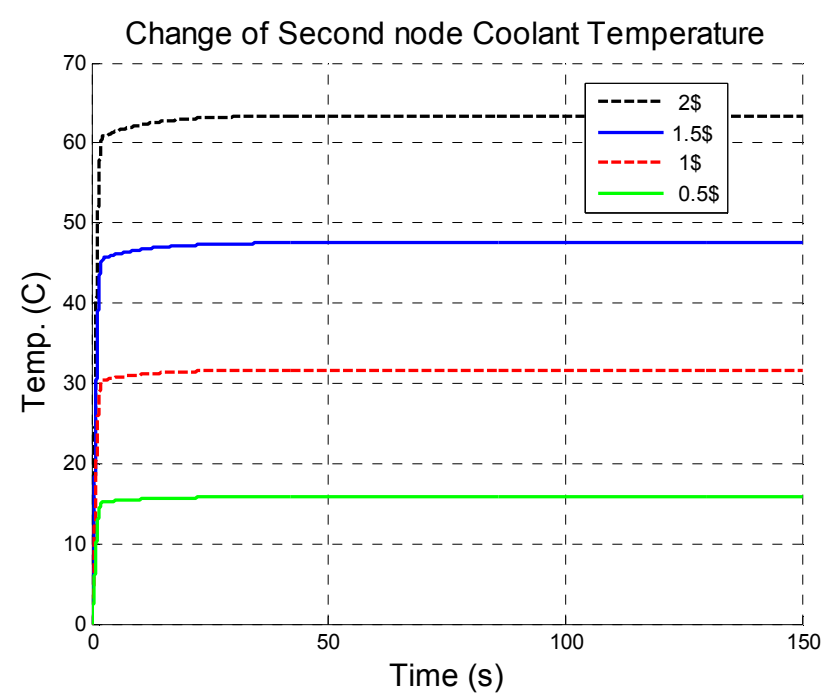

Figure 10. The change of second coolant node temperature. due to different external reactivity.

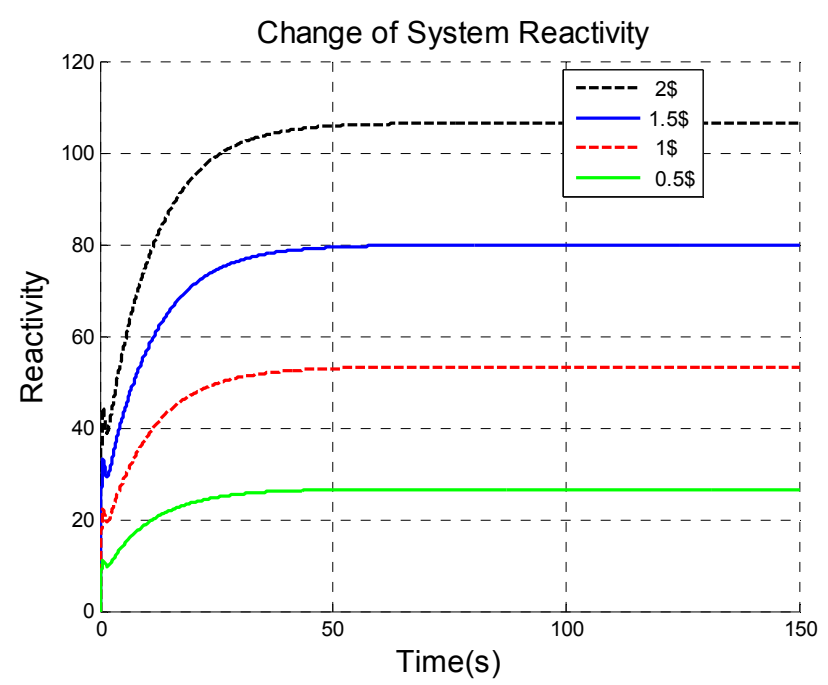

Figure 11. The response of the system Reactivity. due to different external reactivity.

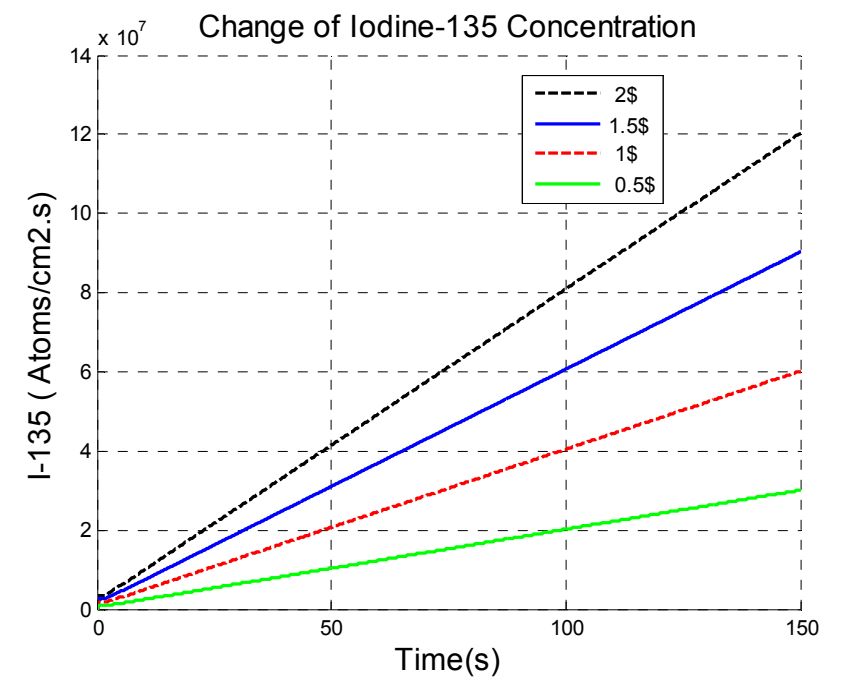

Figure 12. The Change of I-135 Concentrations due to different external activity.

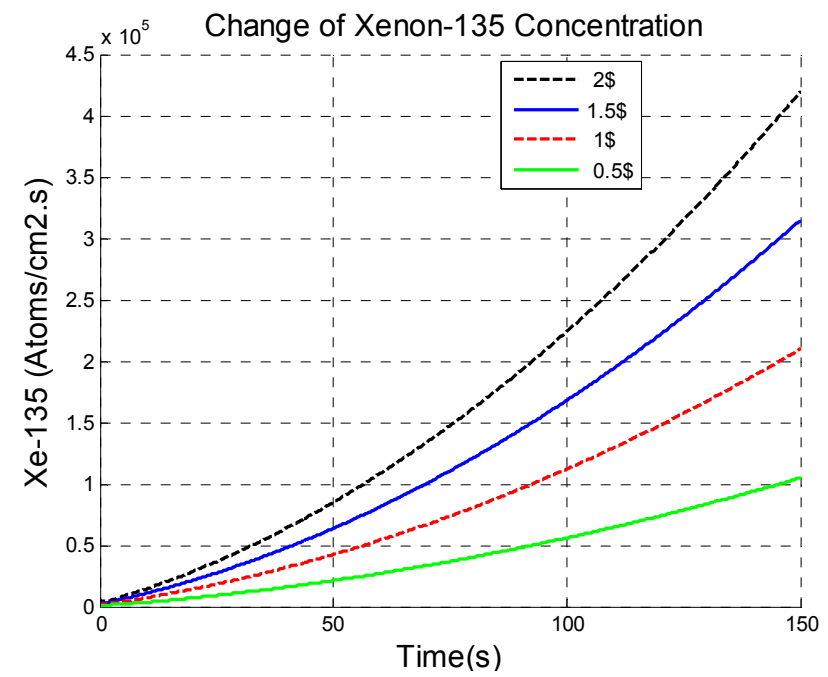

Figure 13. The Change of Xe-135 Concentrations due to different external reactivity. 


\section{Conclusions}

Rod Ejection Accidents (REAs) belongs to Reactivity Initiation Accidents (RIAs) as design base accidents, introducing positive reactivity, that causes power arising sharply thus can lead to sever accidents especially at Hot Zero Power. In this research, a new dynamic model for NuScale SMR is proposed using MATLAB environment using Ordinary Differential Equations for representing the dynamics related to the core reactor kinetics and the thermal hydraulics variations during transient external reactivity accident (rod ejection accidents). The proposed model is validated by comparison its transient responses of step change of external reactivity and inlet temperature with reference [10], the validation results demonstrated that the proposed model has good agreement with the obtained results. The proposed model is verified through many control rods ejection accidents, that cause positive reactivity $[0.5 \$$, $1 \$, 1.5 \$ 2 \$]$ are applied as external reactivity that investigator in reference [11]. The output results, show that the proposed model can predict the reactor responses, during Rod ejection accidents as reactivity initiand accidents and others transient, thus it can be used for safety analysis of the NuScale as SMR during transient such as REAs with other values and also, can be used for safety analysis others types of SMR reactors just by changing the core system parameters.

\section{References}

[1] "Nuclear Fuel Behaviour Under Reactivity-initiated Accident (RIA) Conditions", State-of-the-art Report, OCDE 2010 NEA No. 6847 Nuclear Energy Agency Organisation, for Economic Co-Operation and Development, Nuclear Safety, ISBN 97892-64-99113-2 NEA/CSNI/R (2010)., https://www.oecdnea.org/upload/docs/application/pdf/2019-12/nea6847behaviour-ria.pdf.

[2] Desquines J., et al., "The issue of stress state during mechanical tests to assess cladding performance during a reactivity-initiated accident (RIA)", Journal of Nuclear Materials, 2011, 412: pp. 250-267. https://pennstate.pure.elsevier.com/en/publications/the-issueof-stress-state-during-mechanical-tests-to-assess-cladd.

[3] Magy M. Kandil, "Simulation of Pressurized Water Reactor under Specified Reactivity Accidents", Journal of Multidisciplinary Engineering Science Studies (JMESS) ISSN: 2458-925XVol. 7 Issue 3, March -2021. http://www.jmess.org/wp-

content/uploads/2021/03/JMESSP13420725.pdf.

[4] Diamond D. J., et al., "Studies of the rod ejection accident in a PWR", Technical reportW-6382, Brookhaven National Laboratory, Upton, NY, USA, 2002. https://www.nrc.gov/docs/ML0204/ML020430129.pdf.
[5] Rodney A. Busquim E SILVA, "Implications of advanced computational methods for reactivity initiated accidents in nuclear reactors", Ph. D, Sao Paulo, 2015. https://www.teses.usp.br/teses/disponiveis/3/3139/tde20072016-

142605/publico/RodneyAparecidoBusquimeSilva2015.pdf.

[6] Cammi, A., Ponciroli, R., Borio di Tigliole, A., Magrotti, G., Prata, M., Chiesa, D., Previ-tali, E., 2013. A zero-dimensional model for simulation of TRIGA Mark II dynamic response. Prog. Nucl. Energy 68, 43-54.

[7] Chang, M. H., Sim, S. K., Lee, D. J., 2000. SMART behavior under over-pressurizing accident conditions. Nucl. Eng. Des. 1991 (1), 187-196.

[8] NuScale Plant Design Overview, NP-ER-0000-1198, Rev. 2, NuScale Power, LLC, Corvallis, Oregon, September 2013b., http://pbadupws.nrc.gov/docs/ML1326/ML13266A109.pdf23 0 .

[9] Chireuding Zeliang, Yi Mi, Akira Tokuhiro, Lixuan Lu and Aleksey Rezvoi, "Integral PWR-Type Small Modular Reactor Developmental Status, Design Characteristics and Passive Features: A Review”, Energies 2020, 13 (11), 2898; June 2020.https://doi.org/10.3390/en13112898.

[10] Samet Egemen Arda, "Nonlinear Dynamic Modeling and Simulation of a Passively Cooled Small Modular Reactor", PhD 2016. https://core.ac.uk/download/pdf/79587151.pdf.

[11] Peter Rudling, Lars Olof Jernk, Friedrich Garzarolli, Ron Adamson "Nuclear Fuel Behaviour under RIA Conditions", Advanced Nuclear Technology International, Sweden, December 2016. https://www.researchgate.net/profile/PeterRudling/publication/319065721_Nuclear_Fuel_Behaviour_un der_RIA_Conditions_With_technical_contributions_from_IVI II_Disclaimer_IIVIII/links/598dc16aa6fdcc58acc06293/Nucle ar-Fuel-Behaviour-under-RIA-Conditions-With-technicalcontributions-from-IVIII-Disclaimer-IIVIII.pdf.

[12] Module I: "Nuclear physics and reactor theory," International Atomic Energy Agency, May 2015. https://gnssn.iaea.org/main/bptc/BPTC\%20Module\%20Docu ments/Module $01 \% 20$ Nuclear\%20physics\%20and\%20reactor \%20theory.pdf.

[13] Maria Aranzazu, "Fuel Failure Detection, Characterization and Modelling: Effecton Radionuclide Behaviour in PWR Primary Coolant", Tigeras Menéndez, Ph. D, May 2009. http://oa.upm.es/3267/1/MARIA_ARANZAZU_TIGERAS_ MENENDEZ.pdf.

[14] Thomas W. Kerlin, Belle R. Upadhyaya, "Dynamics and Control of Nuclear Reactors", 1 st edition book, 2019 Elsevier Inc. All rights reserved., website: www.elsevier.com/permissions.

[15] "REACTOR PHYSICS", CNSC, Science and Reactor Fundamentals in Reactor Physics Technical Training Group, January 2003. https://canteach.candu.org/Content\%20Library/20030101.pdf. 